\title{
An Endo-Aesthetic Management of Fractured Maxillary Central Incisors: A Case Report
}

\author{
Authors \\ Shalini*, Megha Narayan, Anamika Rani, Arvind Kumar, \\ Sidhharth Anand, Shikhar Kumar
}

Department of Pedodontics and Preventive dentistry, Buddha Institute of Dental Sciences and Hospital,

Patna, Bihar, India

*Corresponding Author

Shalini

\begin{abstract}
Traumatic dental injuries to anterior maxillary teeth is a frequent incidence in young and adolescent patients. Pedodontist have to deal with these types of serious injuries, in all their day to night routine dental practice. Several studies have reported endodontic management followed by porcelain fused to metal crown restoration using dentine bonding agent and adhesive resin cement for the esthetic concern. This case report presents an endo- esthetic management of maxillary central incisors with crown fracture followed by a permanent restoration.

Keywords: Crown fracture, Adhesive resins, Glass-reinforced composite, Permanent restoration, Porcelain Fused to Metal crown.
\end{abstract}

\section{Introduction}

Traumatic dental injuries (TDI) are very regular, they are mainly derived from blows which can be caused by entity or due to falls, while playing sports as well as injuries sustained during leisure activities and Car accidents. The anterior teeth, of which upper central incisors are more frequently affected and are mostly found ${ }^{1}$. In infants and as well as in youngsters, Coronal fractures of anterior are very much common. Maxillary central incisors are prone to traumatic In the serious dental injuries the Maxillary central dentile are very much prone, Although the maxillary lateral dentile and mandibular central dentile are very less often involved.

TDI located in esthetic areas must be evaluated in several aspects, as: type of smile with teeth, age, tooth energy, involved tissues, location of the fracture and remaining dental structures value or amount.

The path of insertion which is among the fundamental principles of tooth preparation, which is in the retention and resistance form, whereas resistance features prevent restoration dislodgment when oblique, non-axial forces act on the tooth $^{3,4}$. In order to establish suitable diagnosis and design the best therapy to follow, Initial observation plays a Very important and key role,

\section{Case Description}

A male patient aged 13 years with his father reported to outpatient department of pedodontics and preventive dentistry with complaint of broken upper front teeth as a result of trauma due to fall 4 
months back. The complete record have openly revealed thatpatient had trauma because of the fall while he or she was playing with football in a school playground. There was no history of pain. On intraoral examination there was involvement of uncomplicated crown fracture (Ellis class II) with 11 and 21.The fractured line including the enamel (coating) dentin and pulp with respect to 11 and 21 was showed by an intraoral periapical radiography, and also there was a broaden of periodontal ligament with is to the respect to 11 , whereas pulp sensibility test was negative With respect to 11 and 21 , the pulp sensibility was negative, that proved and showed that the teeth were non vital. Clinical and radiographic examination confirmed the Ellis classes IV fractures with 11 and 21. (Fig. 1,2).

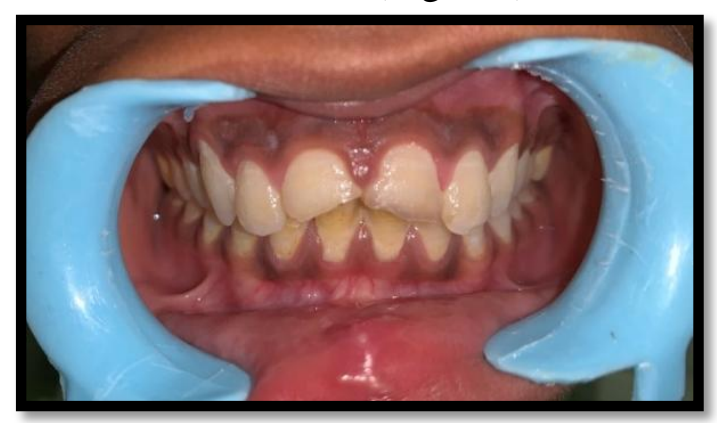

Fig 1

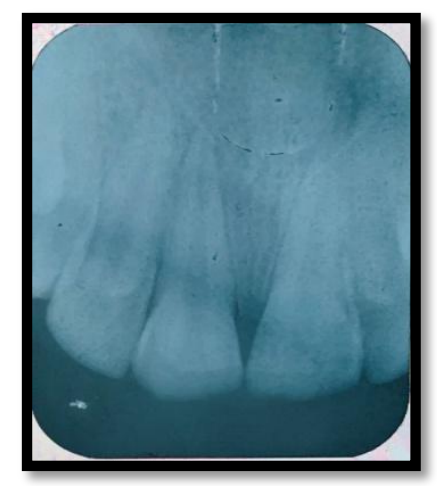

Fig 2

The patient and his father were explained about the treatment procedures in detail and written consent was obtained. Single sitting root canal treatment with respect to 11 and 21 was planned. Earlier to this, oral prophylaxis was made. Access opening was carried out with respect to 11 and 21 , pulp were extirpated and the canals were thoroughly prepared followed by obturation with gutta-percha (Fig. 3). The dentin and enamel of tooth were acid etched with $37 \%$ phosphoric acid
(3M ESPE; Scotch bond TM Multipurpose Etchant, USA) for 20 seconds followed by thorough rinsing for 10 seconds and drying. The cling agent (3M ESPE; Scotch bond TM) was put in and light cured confirming to the manufacturer's directions. Completing and buffing was done (Fig. 4). Obstructions and clearances was discreetly corrected and checked and postoperative directions were given in troop.

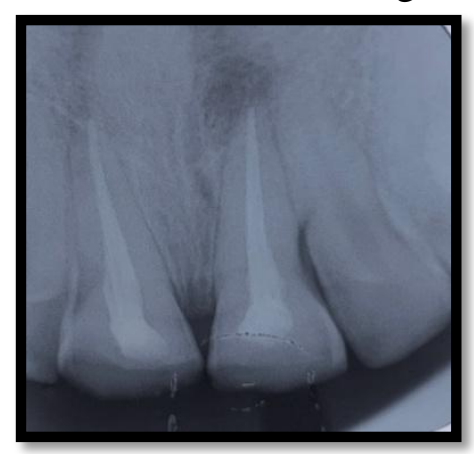

Fig 3

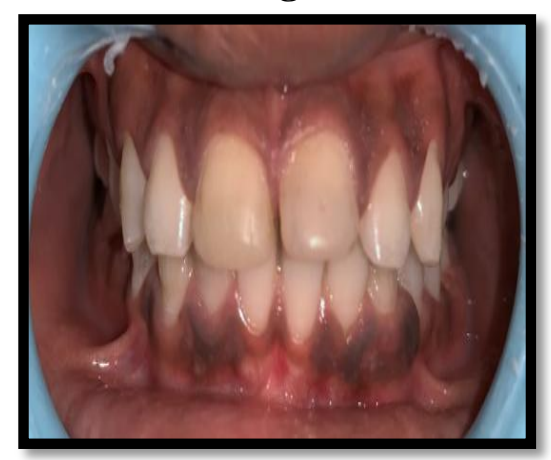

Fig 4

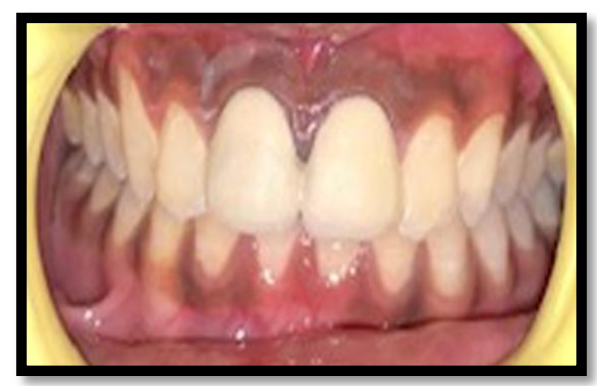

Fig 5

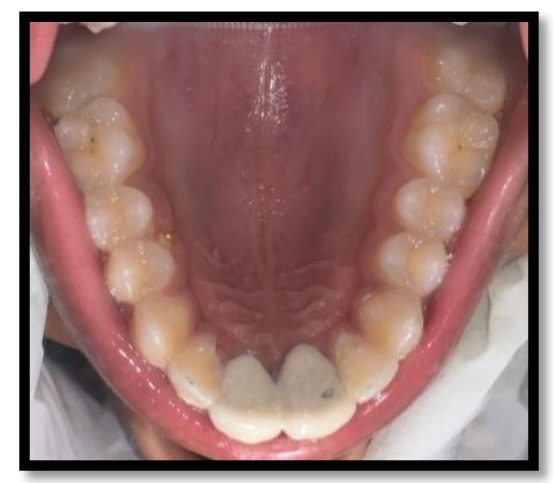

Fig 6 
After 1 week, the patient was recalled. The patient was assessed after 7 days and the tooth 11 and 21 were prepared for full coverage crown, i.e., metal crown fused as porcelain. The tooth were temporary and prepared crown were cemented after 2 days using glass ionomer luting cement (3M ESPE; Ketac TM Cem Radiopaque, Germany; Fig. 5,6). The patient was recalled after 2 weeks for routine checkup followed by 1 month, 6 months, and 12 months follow up (Fig 7).

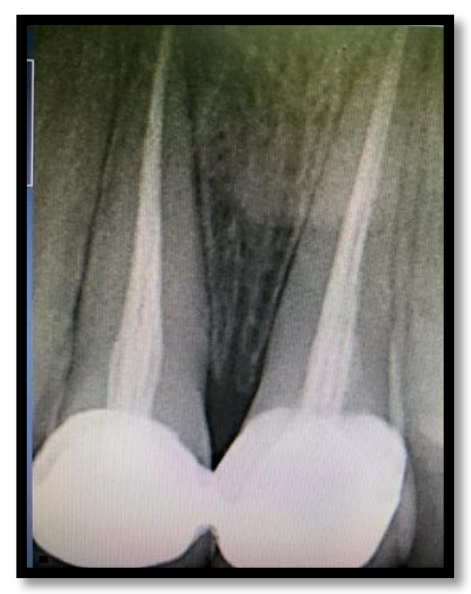

Fig 7: One Month follow up)

\section{Discussion}

Factors for good retention and resistance in PFM restorations includes, size of the tooth, the magnitude of dislodging force, geometry of the tooth preparation and roughness of thepreparation ${ }^{5}$.The most difficult decision in dentistry is to choose upon the best treatment, decision of restoring one or more than that upper dentiles which have been weakened as a result of Traumatic Dental Injury ${ }^{6}$.

Curative decisions are conditioned and made by the need of periodontal and orthodontic contributory care and treatment, as well as the patient's age, thus it is important to consider the need for long term interim crown of polymer ceromers, lithium disilicate and zirconium oxide which are all conventional with respect to leftover structures. For the gold standard for teeth restorations, Metal-porcelain restoration been considered.

To prevail such difficulties, porcelain-fused metal crown was choosed as the forever mending ${ }^{8}$. The management of anterior tooth fracture that has shown better prognosis, functions, esthetics, and satisfaction of patient and parent which are reported in combined techniques. In cases of pulpal involvement an endodontic treatment followed by porcelain fused metal crown can be given.

In present and recent case, glass fiber-reinforced composite post and dual-cure luting sticky composite senario was used and as well as followed by cast mending which delivered superior esthetics and eternity of a non-vital that is dead and fractured tooth.

\section{Conclusion}

The smile is a valuable social communication element and the existing need for exhibiting healthy, functional, harmonious and esthetic teeth. These parameters are therefore the goal to achieve in anterior restorations.

\section{References}

1. Quintero JV, Ayala AH, Plata RG, Szalay ER. Restorative treatment of traumatic dental injuries. Report of three clinical cases. Revista odontológica Mexicana. 2017 Jul 15;21(3):185-97.

2. Macedo GV, Diaz PI, Fernandes AC, et al. Reattachment of anterior teeth fragments: a conservative approach. J Esthet Restor Dent 2008;20(1):5-20. DOI: 10.1111/j.1708-8240.2008.00142.x.

3. Shillingburg H, Hobo S, Whitsett LD, et al. Fundamentals of fixed prosthodontics. Chicago. Quintessence. 2012;119 (130):148-151.

4. Rosenstiel SF, Land MF, Fujimoto J.Contemporary Fixed Prosthodontics, $4^{\text {th }}$ Ed. St. Louis (MO): Mosby Elsevier. 2006;336-375.

5. Shillingburg $\mathrm{H}$, Hobo $\mathrm{S}$, Whitsett LD, et al. Fundamentals of fixed prosthodontics. Chicago. Quintessence. 2012;119(130): 148-151. 
6. Govindarajan M, Reddy VN, Ramalingam K, Durai KS, Rao PA, Prabhu A. Prevalence of traumatic dental injuries to theanterior teeth among three to thirteenyear-old school children of Tamilnadu. Contemp Clin Dent. 2012; 3 (2): 164-167.

7. Jain V, Gupta R, Duggal R, et al. Restoration of traumatized anterior teeth by interdisciplinary approach: report of three cases. J Ind Soc Pedod Prev Dent 2005;23(4):193-197. DOI: 10.4103/09704388.19009.

8. Joshi SR, Pendyala GS, Saraf V, et al. A comprehensive oral and dental management of an epileptic and intellectually deteriorated adolescent. Dent Res J 2013;10(4):562-567. 